\title{
ST6Gal-I expression in ovarian cancer cells promotes an invasive phenotype by altering integrin glycosylation and function Daniel R Christie ${ }^{1}$, Faheem M Shaikh², John A Lucas IV1, John A Lucas III*1 and Susan L Bellis*2
}

\author{
Address: ${ }^{1}$ Department of Obstetrics and Gynecology, University of Alabama at Birmingham, Birmingham, AL 35294, USA and ${ }^{2}$ Department of \\ Physiology and Biophysics, University of Alabama at Birmingham, Birmingham, AL 35294, USA \\ Email: Daniel R Christie - dchristie@uabmc.edu; Faheem M Shaikh - FShaikh@physiology.uab.edu; John A Lucas - jlucas4@uab.edu; \\ John A Lucas* - jlucas@uab.edu; Susan L Bellis* - bellis@physiology.uab.edu \\ * Corresponding authors
}

Published: I October 2008

Journal of Ovarian Research 2008, 1:3 doi:10.1186/1757-2215-1-3

This article is available from: http://www.ovarianresearch.com/content/l/1/3

(C) 2008 Christie et al; licensee BioMed Central Ltd.

This is an Open Access article distributed under the terms of the Creative Commons Attribution License (http://creativecommons.org/licenses/by/2.0), which permits unrestricted use, distribution, and reproduction in any medium, provided the original work is properly cited.
Received: 12 July 2008

Accepted: I October 2008

\begin{abstract}
Background: Ovarian adenocarcinoma is not generally discovered in patients until there has been widespread intraperitoneal dissemination, which is why ovarian cancer is the deadliest gynecologic malignancy. Though incompletely understood, the mechanism of peritoneal metastasis relies on primary tumor cells being able to detach themselves from the tumor, escape normal apoptotic pathways while free floating, and adhere to, and eventually invade through, the peritoneal surface. Our laboratory has previously shown that the Golgi glycosyltransferase, ST6Gal-I, mediates the hypersialylation of $\beta_{1}$ integrins in colon adenocarcinoma, which leads to a more metastatic tumor cell phenotype. Interestingly, ST6Gal-I mRNA is known to be upregulated in metastatic ovarian cancer, therefore the goal of the present study was to determine whether ST6Gal-I confers a similarly aggressive phenotype to ovarian tumor cells.
\end{abstract}

Methods: Three ovarian carcinoma cell lines were screened for ST6Gal-I expression, and two of these, PA-I and SKOV3, were found to produce ST6Gal-I protein. The third cell line, OV4, lacked endogenous ST6Gal-I. In order to understand the effects of ST6Gal-I on cell behavior, OV4 cells were stably-transduced with ST6Gal-I using a lentiviral vector, and integrin-mediated responses were compared in parental and ST6Gal-I-expressing cells.

Results: Forced expression of ST6Gal-I in OV4 cells, resulting in sialylation of $\beta$ I integrins, induced greater cell adhesion to, and migration toward, collagen I. Similarly, ST6Gal-I expressing cells were more invasive through Matrigel.

Conclusion: ST6Gal-I mediated sialylation of $\beta$ I integrins in ovarian cancer cells may contribute to peritoneal metastasis by altering tumor cell adhesion and migration through extracellular matrix.

\section{Background}

The $\alpha 2-6$ linkage of sialic acids to $N$-acetyllactosamine structures (Gal $\beta 1-4 \mathrm{GlcNAc}$ ) is a Golgi-mediated process facilitated by the enzyme, $\beta$-galactoside $\alpha 2-6$-sialyltrans- ferase (ST6Gal-I). Variant $\alpha 2-6$ sialylation can have a wide array of biologic and pathogenic consequences, including alterations in immune response and embryogenesis, as well as a role in the development and progres- 
sion of some cancers [1]. There are several recognized substrates upon which ST6Gal-I is known to act: $\beta 1$ integrin [2], E-selectin, ICAM-1, and VCAM-1 [3]. Perturbation of normal ST6Gal-I functioning fundamentally alters cell behavior by modulating normal cell interactions with the surrounding environment.

The overexpression of ST6Gal-I is well documented in several diverse cancer types. These cancers include: colorectal [4], cervical [5], breast [6], hepatocellular [7], and certain cancers of the head and neck [8]. ST6Gal-I is upregulated by oncogenic ras [9-11] thus accounting for the increased enzyme expression in the various tumor types [2]. Our group has reported that forced expression of ST6Gal-I in SW48 colonocytes, which lack endogenous sialyltransferase activity, caused increased binding to collagen I and laminin, and increased cell motility [12]. This change in cell behavior was shown to be a consequence of the hypersialylation of the $\beta_{1}$ integrin. Though incompletely understood, $\beta_{1}$ hypersialylation could modify integrindependent cell responses through a change in receptor conformation, by masking functional domains within the integrin heterodimer, by affecting integrin interaction with other membrane bound proteins or glycolipids, or by another, as yet, unrecognized mechanism [2]. Lin and colleagues demonstrated that forced expression of ST6Gal-I in MDA-MB-435 human mammary carcinoma cells resulted in increased adhesion to collagen IV, reduced cell-cell adhesion, and increased capacity for invasion [13]. Conversely, introduction of antisense oligonucleotides to ST6Gal-I in colon cancer cells reduced the cells' ability to form colonies and to invade [14]. Taken in sum, these results suggest that overexpression of ST6Gal-I results in a phenotype consistent with aggressive metastasis. In fact, increased tumor levels of ST6Gal-I have been correlated with poorer patient prognosis $[15,6]$, though there are also reports suggesting that ST6Gal-I activity is not predictive of outcome $[16,17]$.

The role of ST6Gal-I in ovarian carcinoma has not been as clearly defined as its effect in some other tumors, namely colon and breast. Nonetheless, there are recent data indicative of the emerging attention to the importance of sialylation in ovarian cancer. High-throughput techniques have yielded evidence that ST6Gal-I is up-regulated in epithelial ovarian malignancy. For example, proteomic analysis revealed $\alpha 2-6$ sialylation to be proportionally favored over $\alpha 2-3$ sialylation [18]. This mirrors the results of Wang and colleagues who showed increased mRNA levels of ST6Gal-I and decreased levels of the $\alpha 2-3$ sialyltransferase, ST3Gal-VI in ovarian cancer [19]. These enzymes can compete for the linkage of sialic acids to terminal Gal $\beta 1-4 \mathrm{GlcNAc}$, and thus the findings indicate that there is preference for $\alpha 2-6$ sialylation in the ovary with malignant transformation. Despite these observed differences in ST6Gal-I mRNA and global cell surface sialylation, a direct examination of ST6Gal-I protein in ovarian tumor cells has not previously been attempted. As well, there is limited information regarding the functional consequences of ST6Gal-I upregulation in ovarian carcinoma. Casey and colleagues treated OVCAR5 ovarian carcinoma cells with neuraminidase enzyme to remove sialic acids and found that this decreased migration toward fibronectin, and reduced invasion through Matrigel [20]. However, the neuraminidase enzyme does not discriminate between $\alpha 2-6$ and $\alpha 2-3$-linked sialic acids, and therefore the changes in cell migration and invasion could not be directly ascribed to ST6Gal-I activity.

In the present study, we screened three separate ovarian carcinoma cell lines for endogenous expression of ST6Gal-I, and found that two of these were positive for ST6Gal-I protein. The third, the OV4 cell line, had negligible levels of the enzyme and therefore, to assess the effects of $\alpha 2-6$ sialylation on promoting the tumor cell phenotype, we forced ST6Gal-I expression and evaluated integrin-dependent cell behaviors. ST6Gal-I expression, with consequent $\beta_{1}$ integrin hypersialylation, induced increased adhesion to collagen I, migration toward collagen I, and invasiveness through Matrigel. Our results suggest a potential role for variant sialylation in the dissemination of ovarian carcinoma.

\section{Methods}

\section{Ovarian carcinoma cell lines}

The ovarian carcinoma cell line SKOV3 was generously gifted to us by Dr. Janet Price (MD Anderson, Houston, TX), whereas the OV4 cell line was a generous gift from Dr. Timothy Eberlein (Harvard, Cambridge, MA). The PA1 cell line was purchased commercially through ATCC (Manassas, VA). PA1 cells were cultured and grown in Eagle's minimal essential medium (MEM) supplemented with $10 \%$ fetal bovine serum (FBS, Hyclone, Logan, UT) and penicillin, streptomycin, and amphotericin B. OV4 and SKOV3 cells were cultured and grown in Dulbecco's modified Eagle's MEM/Ham's F-12 50:50 (DMEM/F12) supplemented with $10 \%$ FBS, penicillin, streptomycin, and amphotericin B. Cells were maintained at $37^{\circ} \mathrm{C}$ in $5 \%$ $\mathrm{CO}_{2}$ and passaged two to three times per week.

\section{Western blotting}

Cells were lysed in buffer composed of $50 \mathrm{mM}$ Tris- $\mathrm{HCl}$ ( $\mathrm{pH} 7.4$ ) containing $1 \%$ Triton $\mathrm{X}-100$, and a protease inhibitor cocktail (Roche Applied Bioscience). Protein concentrations of the lysates were determined using a modified Bradford Assay (Sigma, St. Louis, MO). Proteins were resolved by reducing SDS-PAGE, and transferred to polyvinylidene difluoride membranes. Membranes were blocked with 5\% nonfat dry milk in TBS containing $0.05 \%$ Tween 20 (TBST). Primary antibodies were then 
added to the membranes for incubation, with antibody against ST6Gal-I (a monoclonal generated by the UAB Hybridoma Core Facility), $\beta_{1}$ integrin (Transduction Laboratories, Lexington, KY), or the V5 epitope (Invitrogen, Carlsbad, CA). Membranes were then washed and incubated with horseradish peroxidase-coupled secondary antibody (Amersham, Piscataway, NJ). The labeled proteins were visualized with enhanced chemiluminescence, and subsequent images were scanned with a HewlettPackard Scanjet 5470 c (Wilmington, DE).

\section{SNA-I lectin affinity assay}

Cell lysates were incubated overnight at $4{ }^{\circ} \mathrm{C}$ with rotation with $100 \mu \mathrm{g} / \mathrm{mL}$ of the $\alpha 2-6$ sialic acid-specific lectin, SNA-1, conjugated to agarose beads (Vector Laboratories, Burlingame, CA). The lectin-glycoprotein complexes were collected by centrifugation, washed with lysis buffer, and released from the bead complexes by boiling in SDSPAGE sample buffer. Precipitated proteins were resolved by reducing SDS-PAGE, and immunoblotted to detect $\beta_{1}$ integrin.

\section{Stable ST6Gal-I transduction of OV4 cells}

An ST6Gal-I cDNA construct, containing a C-terminal V5 tag, was a generous gift from Dr. Karen Colley (University of Illinois, Chicago). This construct was incorporated into a lentiviral vector containing a puromycin-resistance cassette for selection of stably-transduced cells, as previously described [12]. OV4 cells were transduced with the ST6Gal-I lentivirus, and a pooled population of stable clones was obtained by puromycin selection. As a control, OV4 cells were transduced with a lentiviral construct lacking ST6Gal-I ("empty vector" cells). Stable expression of ST6Gal-I was confirmed by immunoblotting for ST6Gal-I, as well as the V5 tag.

\section{Cell adhesion assay}

The parental (P), ST6Gal-I-expressing (ST6), and empty vector-transduced (EV) cells were cultured in serum-free DMEM/F12 media for 48 hours. Cells were disengaged from the culture flasks using CellStripper solution (Cellgro, Herndon, VA) and $8 \times 10^{4}$ cells were plated onto culture dishes pretreated with $20 \mu \mathrm{g} / \mathrm{mL}$ bovine collagen I and blocked with $2 \%$ denatured bovine serum albumin (dBSA). To control for nonspecific binding, cells were also plated onto dishes pretreated with dBSA alone. Cells were allowed to adhere for 30 minutes at $37^{\circ} \mathrm{C}$, and then samples were washed gently with PBS. The remaining adherent cells were fixed using formaldehyde and $4 \%$ sucrose, and subsequently stained with crystal violet and solubilized with $10 \%$ acetic acid. Absorbance of the solution dye was measured at $540 \mathrm{~nm}$.

\section{Haptotactic collagen I cell migration assay}

P, ST6, and EV cells were cultured in serum-free media for 48 hours and disengaged from the culture dishes using CellStripper solution. $2.5 \times 10^{5}$ cells were then seeded into the upper wells of Boyden chambers included in the QCM Collagen I Quantitative Cell Migration Assay Kit (Chemicon International). The chambers were lined with $8.0 \mu \mathrm{m}$ polyethylene terpthalate (PET) membranes coated on the underside with a collagen I concentration gradient. To control for nonspecific migration, cells were also seeded into Boyden chambers with PET membranes coated with BSA. The lower chambers contained $300 \mu \mathrm{L}$ of conditioned, serum-free NIH3T3 media for the chemoattractant. Cells were allowed to incubate at $37^{\circ} \mathrm{C}$ for 14 hours, and migration to the underside of the membrane was quantified as per the vendor's staining protocol.

\section{Cell invasion assay}

P, ST6, and EV cells were cultured in serum-free DMEM/ F12 media for 48 hours prior to being disengaged from the culture flasks using CellStripper solution. BD BioCoat Growth Factor Reduced (GFR) Matrigel Invasion Chamber (BD Biosciences, San Jose, CA) assay kits were used to measure invasion. $5 \times 10^{5}$ cells were seeded into the upper wells of Boyden chambers lined with $8.0 \mu \mathrm{m}$ PET membranes with a thin layer of GFR Matrigel Basement Membrane Matrix. The lower chamber contained $300 \mu \mathrm{L}$ of conditioned, serum-free NIH3T3 media for the chemoattractant. Cells were incubated at $37^{\circ} \mathrm{C}$ for 48 hours, and invasion was quantified as per the vendor's staining protocol.

\section{Results \\ A screen of three ovarian carcinoma cell lines reveals differing levels of ST6Gal-I expression}

Levels of ST6Gal-I mRNA have been shown to be increased in ovarian carcinoma [19], but, to date, there is no published work characterizing ST6Gal-I protein levels, or its activity in vitro or in vivo. We chose three established ovarian carcinoma cell lines to screen for the enzyme: PA1, OV4, and SKOV3. To this end, cells were lysed and immunoblotted for ST6Gal-I. As shown in Fig. 1, PA1 demonstrated the highest expression of ST6Gal-I, while OV4 had negligible levels. Expression level in SKOV3 cells was also low relative to PA-1, but significantly higher than in OV-4 cells.

\section{The level of expression of ST6Gal-I is predictive of $\beta I$ integrin hypersialylation}

To assess levels of $\alpha 2-6$ sialylation on the ST6Gal-I substrate, $\beta_{1}$ integrin, we evaluated integrin reactivity to SNA1 , a lectin which specifically recognizes $\alpha 2-6$-linked sialic acids. Briefly, cell lysates were incubated with agaroseconjugated SNA-1, and SNA-bound glycoproteins were then collected by centrifugation. The glycoproteins were 


\section{OV4 SKOV3 PA1}

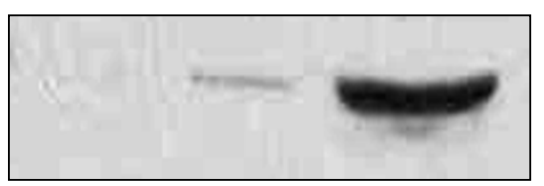

\section{ST6Gal-I}

Figure I

Screen of three ovarian carcinoma cell lines for ST6Gal-I expression. PAI, OV4, and SKOV3 cells were grown in culture, lysed, resolved under reducing conditions with SDS-PAGE, and then immunoblotted for ST6Gal-I.

resolved by SDS-PAGE, and Western blotted for $\beta_{1}$ integrin (Fig. 2A). In line with the relative amount of ST6Gal-I expression, PA1 had the highest amount of $\alpha 2-$ 6 sialylation of $\beta_{1}$ integrin, followed by SKOV3, with OV4 having no detectable $\alpha 2-6$ sialylation of its $\beta_{1}$ integrin. PA1, SKOV3 and OV4 cell lysates were also immunoblotted for total amounts of $\beta_{1}$ integrin, which revealed comparable levels of the protein in the three cell lines (Fig. 2B). Interestingly, the higher molecular weight band in $\beta_{1}$ immunoblots ("mature" isoform, representing the functional receptor) displayed variable electrophoretic mobility for the three cell lines, with the bands from PA1 and

\section{A}

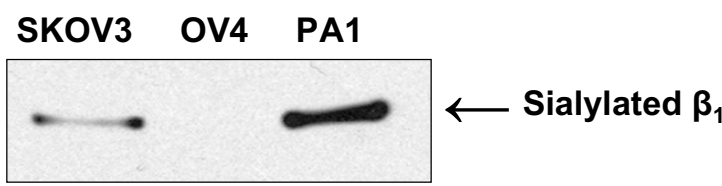

B

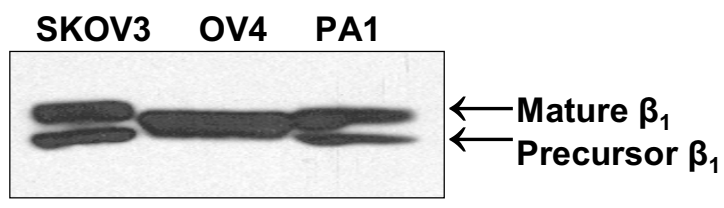

Figure 2

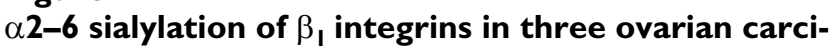
noma cell lines.A, Lysates from PAI, OV4, and SKOV3 cells were incubated with agarose-conjugated SNA, a lectin specific for $\alpha 2-6$ sialic acids. Glycoproteins were precipitated, resolved by SDS-PAGE and immunoblotted for the $\beta_{\text {I }}$ integrin. $\boldsymbol{B}$, Cell lysates were immunoblotted for the $\beta_{\text {I }}$ integrin to control for total levels of protein expression. The

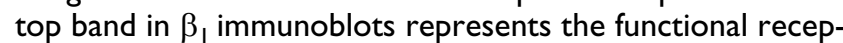
tor isoform ("mature $\beta_{\text {I }}$ "), whereas the bottom band represents a precursor, ER-resident, form of $\beta_{1}$. Of note, OV4 cells do not appear to express a precursor isoform.
SKOV3 cells showing reduced mobility. As we have previously reported, changes in electrophoretic mobility of the mature $\beta_{1}$ integrin isoform typically reflect variation in the degree of $\alpha 2-6$ sialylation $[12,21]$. Thus, the increased apparent molecular mass of mature integrins expressed by PA1 and SKOV3 cells is consistent with the observation that these integrins are more heavily sialylated. Of note, the lower band in $\beta_{1}$ immunoblots is thought to represent a precursor integrin isoform localized to the endoplasmic reticulum, and as such, is not a substrate for ST6Gal-I. The precursor isoform was not observed in OV4 cells.

\section{Forced expression of ST6Gal-I in OV4}

In order to illustrate the role of $\alpha 2-6$ sialylation in modifying integrin-dependent cell behaviors, OV4 cells were stably transduced with a lentiviral vector containing a V5tagged ST6Gal-I construct (ST6). An empty-vector control cell line (EV) was also generated (note that these cell lines represent a pooled population of stably-transduced clones). Expression of the ST6Gal-I construct was confirmed by Western blotting for both ST6Gal-I and for the V5 tag (Fig. 3A). Neither the parental (P) nor EV cells

A

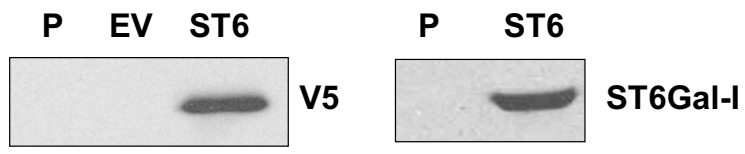

B
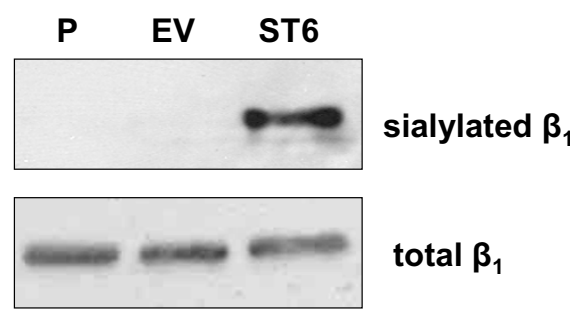

Figure 3

$\alpha 2-6$ sialylation of $\beta_{\text {I }}$ integrins in ST6Gal-I-expressing OV4 cells. Parental OV4 cells (P) were stably transduced with a lentiviral vector encoding an ST6Gal-I cDNA fused to a V5 tag (ST6). Cells were also transduced with an empty lentiviral vector as a control (EV). A, Cell lysates were immunoblotted for the V5 tag (left panel) or for ST6Gal-I (right panel) to verify successful transduction of the ST6Gal-I construct. B, Lysates from P, EV, and ST6 cells were SNA-precipitated and immunoblotted for $\beta_{1}$ integrins to monitor levels of integrin sialylation. Lysates were also immunoblot-

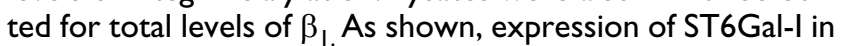
OV 4 cells caused $\beta_{1}$ integrins to become $\alpha 2-6$ sialylated, verifying that the transduced enzyme was active. 
showed a detectable signal, whereas the ST6 cells showed a strong signal for both ST6Gal-I and the V5 tag.

In order to demonstrate that the ST6Gal-I construct was functionally active, SNA was used to precipitate $\alpha 2-6$ sialylated glycoproteins as described above. The precipitates were then Western blotted for the $\beta_{1}$ integrin, and, as expected, only the $\beta_{1}$ integrins from ST6Gal-I expressing cells were found to be $\alpha 2-6$ sialylated (Fig 3B).

\section{Cells expressing ST6Gal-I show greater adhesion to collagen I}

Collagen $I$ is a known $\beta_{1}$ integrin ligand, and cell attachment to collagen I is integrin-mediated. We have previously reported that $\alpha 2-6$ sialylation of $\beta_{1}$ integrins enhances the adhesion of colon carcinoma cells to collagen I [12]. Thus, OV4 cells were monitored for binding to collagen I. As shown in Fig. 4, attachment to collagen I was significantly increased in the ST6 cells compared with $\mathrm{P}(\mathrm{p}<0.01)$ and EV $(\mathrm{p}<0.05)$ cells. There was no difference in binding to collagen I between $\mathrm{P}$ and $\mathrm{EV}$.

\section{Cells expressing ST6Gal-I show increased haptotactic migration on collagen I}

A hallmark of advanced ovarian carcinoma is intraperitoneal spread, and therefore cancer cells with a phenotype that includes increased migration might be more apt to metastasize. To evaluate the migratory properties conferred to the OV4 cell line by $\alpha 2-6$ sialylation, we compared the cell lines in a Boyden chamber coated on its underside with a collagen I concentration gradient. Conditioned serum-free NIH 3T3 media was used as a chemoattractant. As shown in Fig. 5A, ST6 cells were more

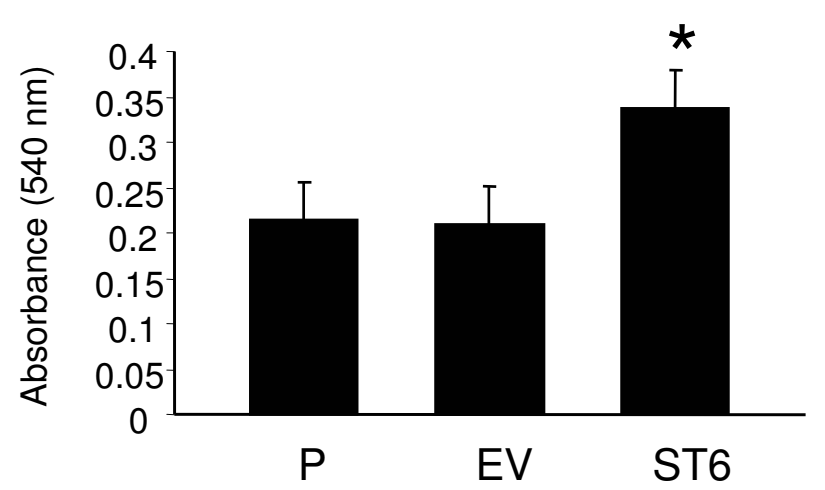

Figure 4

Cell adhesion to collagen I. OV4 cells (P, EV, and ST6) were seeded onto culture dishes coated with collagen I, and binding was quantified using a standard crystal violet straining protocol. Data represent means and SEMs of three independent experiments run in triplicate. * denotes $\mathrm{P}<0.05$, evaluated by ANOVA.
Cell Migration
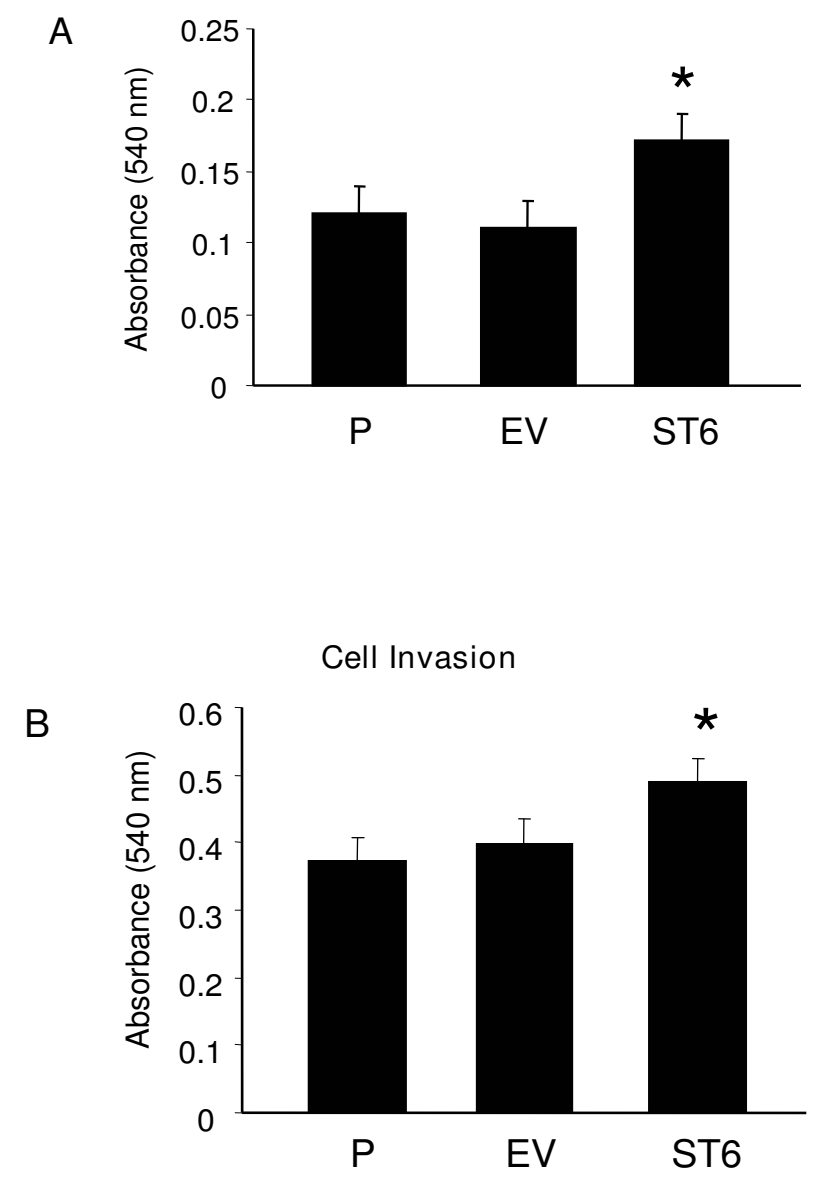

Figure 5

A, Haptotactic migration toward collagen I. P, EV, and ST6 cells were serum starved for $\mathbf{4 8}$ hours. Cells were then seeded in serum-free media into the upper wells of Boyden chambers lined with $8.0 \mu \mathrm{m}$ PET membranes coated on the underside with a collagen I. The lower chambers contained conditioned NIH3T3 media as a chemoattractant. Cells were allowed to migrate for 14 hours, and cell migration was quantified using the vendor's protocol. B, Invasion of OV4 cells through Matrigel-coated transwells. P, EV, and ST 6 cells were serum starved for 48 hours, and then seeded into the upper wells of Boyden chambers lined with Matrigel-coated $8.0 \mu \mathrm{m}$ PET membranes. The lower chambers contained condition NIH3T3 media as a chemoattractant. Cells were allowed to invade for $\mathbf{4 8}$ hours and invasion was quantified using the vendor's protocol. Data represent means and SEMs of three independent experiments run in triplicate. * denotes $\mathrm{P}<0.0 \mathrm{I}$, evaluated by ANOVA. 
migratory than either P ( $p<0.001)$ or EV ( $p<0.001)$ cells. There was no difference between $\mathrm{P}$ and EV migration.

\section{Cells expressing ST6Gal-I show increased invasion}

To determine whether up-regulated ST6Gal-I confers a more invasive phenotype, a cell invasion assay was run. More specifically, cells were applied to the top of a layer of growth-factor reduced Matrigel, coated on the top of a transwell filter. Cells were seeded in serum-free media, with conditioned NIH 3T3 media in the lower chamber as a chemoattractant. Cells were allowed to invade for 48 hours, and the cells migrating through the Matrigel to the underside of the filter were quantified. As shown in Fig. $5 \mathrm{~B}$, the ST6 cells were more invasive than either $\mathrm{P}(\mathrm{p}<$ $0.05)$, or EV ( $\mathrm{p}<0.05)$. No difference was observed in the invasiveness of $\mathrm{P}$ and $\mathrm{EV}$ cells.

\section{Discussion}

Peritoneal metastasis of epithelial ovarian carcinoma is the primary means of metastatic spread, although a small minority of tumors disseminate via hematogenous or lymphatic routes. At the time of diagnosis, about $70 \%$ of patients will have peritoneal spread of the disease, indicative of advanced stage (III-IV), which confers a worse prognosis than if the disease were discovered at an earlier stage. Though the process of peritoneal seeding is poorly understood, the most widely accepted hypothesis is that cells detach from the primary tumor, and are transported via peritoneal fluid throughout the abdomen, eventually attaching themselves to the peritoneal surface. Phenotypically, the tumor cells with the best chance of metastasizing are cells with the ability to escape apoptosis following detachment, while exhibiting increased capacity to adhere to, and invade through the peritoneum, which is exactly the cellular phenotype routinely seen in advanced stage ovarian carcinoma [22]. In the present study, we show that forced expression of ST6Gal-I in ovarian epithelial cells, resulting in $\alpha 2-6$ sialylation of $\beta_{1}$ integrins, induces increased adhesion and migration on collagen I and invasion through Matrigel. These results suggest that upregulation of ST6Gal-I in ovarian carcinoma may confer a more metastatic phenotype, which mirrors the findings of others' work with colon and breast cancers $[13,12]$.

The regulation of ST6Gal-I expression is multifactorial. Its expression is increased by oncogenic ras [9-11], though a ras mutation is only present in approximately $6 \%$ of epithelial ovarian cancers [23]. However, even in the absence of a ras mutation, perturbations in the ras signaling pathway can lead to physiologically activated H-ras, which can be present in as much as $60 \%$ of ovarian tumors [24]. Cytokines, such as TNF- $\alpha$, IL-1, and IL-6, can also induce expression of ST6Gal-I $[25,26]$, and interestingly, IL-1 and IL-6 have been shown to increase ovarian carcinoma cell motility and metastasis, as well as being able to up-regu- late TNF- $\alpha$ production $[27,28]$. Finally, there are data to suggest that steroidal regulation of ST6Gal-I may be of importance in ovarian cancer. Corticosteroids up-regulate a2-6 sialyltransferase activity in vivo $[29,30]$, and increase ST6Gal-I mRNA expression in vitro [31]. Further, cortisol has been shown to increase invasiveness in the SKOV3 cell line in vitro [32]. Estradiol $\left(\mathrm{E}_{2}\right)$ decreases ST6Gal-I expression in a dose dependent fashion in the human breast cancer cell line, MCF-7, an effect reversed with Tamoxifen [33]. A lack of responsiveness to $E_{2}$ in ovarian cancers has been demonstrated in SKOV3 to be due to a mutation in estrogen receptor- $\alpha$ [34], and thus is a plausible explanation for the hypersialylated phenotype despite an estrogenic microenvironment. Based on our findings in the present study, $\alpha 2-6$-hypersialylation may contribute to the invasive phenotype induced by these various modalities by altering the function of the $\beta_{1}$ integrin receptor.

We have previously shown that ST6Gal-I-mediated sialylation of $\beta_{1}$ integrins expressed by colon tumor cells increases cell adhesion to, and migration on collagen I [12]. Likewise, $\alpha 2-6$ sialylation of purified integrin receptors enhances receptor binding to collagen I, confirming a critical role for sialylation in regulating integrin function. Collagen I has been shown to be secreted in vitro by LP9 mesothelial cells, along with fibronectin, laminin, vitronectin, and collagen types III and IV. In vivo, these molecules would contribute to the make up of the extracellular matrix (ECM) that free floating ovarian carcinoma cells would encounter, adhere to, and subsequently invade [35]. $\beta_{1}$ integrin's importance in the metastasis of ovarian cancer has been repeatedly demonstrated. $\beta_{1}$ integrin is integral to multicellular spheroid formation [36], adhesion to peritoneal mesothelium [35,37], migration toward a variety of ECM molecules [38], and spheroid disaggregation and invasion [39]. Most studies of altered $\beta_{1}$ function have focused on either changes in integrin expression or regulation of activity through "inside-out" signaling mechanisms (e.g., conformational changes elicited by the binding of cytosolic molecules to integrin cytoplasmic tails). However, there is growing appreciation for the role of variant sialylation in modulating $\beta_{1}$ activity.

Given the extensive evidence of hypersialylation in tumor progression, sialyltransferases have been investigated as potential targets for drug therapy [40]. ST6Gal-I acts to catalyze the transfer of the activated sialyl residue from a sugar nucleotide donor to a glycoconjugate acceptor. Strategies designed to halt this process can be aimed at competitively inhibiting the donor with a sugar nucleotide analog, or with an analog of the transition state which binds with many order higher affinity to sialyltransferases than do ground state analogs [41], or by inhibiting the acceptor with a glucoconjugate analog. 
Another promising avenue of sialyltransferase inhibition is with antisense-oligodeoxynucleotides, which reduce cell surface sialylation without affecting overall cell viability or growth [42]. Challenges remain in developing a sialyltransferase inhibitor that is readily bioavailable, but several strategies to circumvent these problems are under investigation.

\section{Conclusion}

In this study, we have shown that cell behaviors consistent with a metastatic phenotype can be induced in ovarian tumor cells by upregulation of ST6Gal-I, with consequent 22-6 sialylation of $\beta_{1}$ integrins. Overexpression of ST6Gal-I has previously been implicated in colorectal and breast adenocarcinomas, however, only limited information has been available regarding the role of this enzyme in ovarian cancer. The accumulating evidence indicating that ST6Gal-I-mediated integrin sialylation causes increased cell migration and invasion in multiple tumor types suggests that ST6Gal-I is a promising target for therapeutic intervention.

\section{Authors' contributions}

DRC, FMS and JAL IV were directly involved in data acquisition and analysis. DRC wrote the manuscript with editorial assistance from JAL III and SLB. DRC, SLB and JAL III were responsible for the initial conception and design of the study.

\section{Acknowledgements}

This investigation was supported by NIH grant R0ICA84248 (SLB).

\section{References}

I. Varki NM, Varki A: Diversity in cell surface sialic acid presentations: implications for biology and disease. Lab lnvest 2007, 87:85I-857.

2. Bellis SL: Variant glycosylation: an underappreciated regulatory mechanism for betal integrins. Biochim Biophys Acta 2004, 1663:52-60.

3. Dall'Olio F: The sialyl-alpha2,6-lactosaminyl-structure: biosynthesis and functional role. Glycoconj J 2000, 17:669-676.

4. Dall'Olio F, Chiricolo M, Lau JT: Differential expression of the hepatic transcript of beta-galactoside alpha2,6-sialyltransferase in human colon cancer cell lines. Int J Cancer 1999, 81:243-247.

5. Wang PH, Lee WL, Lee YR, Juang CM, Chen YJ, Chao HT, Tsai YC, Yuan CC: Enhanced expression of alpha 2,6-sialyltransferase ST6Gal I in cervical squamous cell carcinoma. Gynecol Oncol 2003, 89:395-40I.

6. Recchi MA, Hebbar M, Hornez L, Harduin-Lepers A, Peyrat JP, Delannoy $P$ : Multiplex reverse transcription polymerase chain reaction assessment of sialyltransferase expression in human breast cancer. Cancer Res 1998, 58:4066-4070.

7. Pousset D, Piller V, Bureaud N, Monsigny M, Piller F: Increased alpha2,6 sialylation of $\mathbf{N}$-glycans in a transgenic mouse model of hepatocellular carcinoma. Cancer Res 1997, 57:4249-4256.

8. Bergler W, Riedel F, Schwartz-Albiez R, Gross HJ, Hormann K: A new histobiochemical method to analyze sialylation on cellsurface glycoproteins of head and neck squamous-cell carcinomas. Eur Arch Otorhinolaryngol 1997, 254:437-44I.

9. Dalziel M, Dall'Olio F, Mungul A, Piller V, Piller F: Ras oncogene induces beta-galactoside alpha2,6-sialyltransferase (ST6Gal
I) via a RaIGEF-mediated signal to its housekeeping promoter. Eur J Biochem 2004, 271:3623-3634.

10. Le Marer N, Laudet V, Svensson EC, Cazlaris H, Van Hille B, Lagrou C, Stehelin D, Montreuil J, Verbert A, Delannoy P: The c-Ha-ras oncogene induces increased expression of beta-galactoside alpha-2, 6-sialyltransferase in rat fibroblast (FR3T3) cells. Glycobiology 1992, 2:49-56.

II. Seales EC, Jurado GA, Singhal A, Bellis SL: Ras oncogene directs expression of a differentially sialylated, functionally altered betal integrin. Oncogene 2003, 22:7|37-7|45

12. Seales EC, Jurado GA, Brunson BA, Wakefield JK, Frost AR, Bellis SL: Hypersialylation of betal integrins, observed in colon adenocarcinoma, may contribute to cancer progression by upregulating cell motility. Cancer Res 2005, 65:4645-4652.

13. Lin S, Kemmner W, Grigull S, Schlag PM: Cell surface alpha 2,6 sialylation affects adhesion of breast carcinoma cells. Exp Cell Res 2002, 276: $101-110$.

14. Zhu Y, Srivatana U, Ullah A, Gagneja H, Berenson CS, Lance P: Suppression of a sialyltransferase by antisense DNA reduces invasiveness of human colon cancer cells in vitro. Biochim Biophys Acta 200I, 1536: I48-160.

15. Lise M, Belluco C, Perera SP, Patel R, Thomas P, Ganguly A: Clinical correlations of alpha2,6-sialyltransferase expression in colorectal cancer patients. Hybridoma 2000, 19:281-286.

16. Poon TC, Chiu CH, Lai PB, Mok TS, Zee B, Chan AT, Sung JJ, Johnson PJ: Correlation and prognostic significance of beta-galactoside alpha-2,6-sialyltransferase and serum monosialylated alpha-fetoprotein in hepatocellular carcinoma. World J Gastroenterol 2005, I I:670I-6706.

17. Vazquez-Martin C, Gil-Martin E, Fernandez-Briera A: Elevation of ST6Gal I activity in malignant and transitional tissue in human colorectal cancer. Oncology 2005, 69:436-444.

18. Saldova R, Royle L, Radcliffe CM, Abd Hamid UM, Evans R, Arnold JN, Banks RE, Hutson R, Harvey DJ, Antrobus R, Petrescu SM, Dwek RA, Rudd PM: Ovarian cancer is associated with changes in glycosylation in both acute-phase proteins and IgG. Glycobiology 2007, I 7:1344- I356.

19. Wang PH, Lee WL, Juang CM, Yang YH, Lo WH, Lai CR, Hsieh SL, Yuan CC: Altered mRNA expressions of sialyltransferases in ovarian cancers. Gynecol Oncol 2005, 99:631-639.

20. Casey RC, Oegema TR Jr, Skubitz KM, Pambuccian SE, Grindle SM, Skubitz AP: Cell membrane glycosylation mediates the adhesion, migration, and invasion of ovarian carcinoma cells. Clin Exp Metastasis 2003, 20: I 143-I52.

21. Semel AC, Seales EC, Singhal A, Eklund EA, Colley KJ, Bellis SL: Hyposialylation of integrins stimulates the activity of myeloid fibronectin receptors. J Biol Chem 2002, 277:32830-32836.

22. Lee JM, Dedhar S, Kalluri R, Thompson EW: The epithelial-mesenchymal transition: new insights in signaling, development, and disease. I Cell Biol 2006, I72:973-98I.

23. Varras MN, Sourvinos G, Diakomanolis E, Koumantakis E, Flouris GA, Lekka-Katsouli J, Michalas S, Spandidos DA: Detection and clinical correlations of ras gene mutations in human ovarian tumors. Oncology 1999, 56:89-96.

24. Patton SE, Martin ML, Nelsen LL, Fang X, Mills GB, Bast RC Jr, Ostrowski MC: Activation of the ras-mitogen-activated protein kinase pathway and phosphorylation of ets-2 at position threonine 72 in human ovarian cancer cell lines. Cancer Res 1998, 58:2253-2259.

25. Dalziel M, Lemaire S, Ewing J, Kobayashi L, Lau JT: Hepatic acute phase induction of murine beta-galactoside alpha 2,6 sialyltransferase (ST6Gal I) is IL-6 dependent and mediated by elevation of exon $\mathrm{H}$-containing class of transcripts. Glycobiology 1999, 9:1003-1008.

26. Hanasaki K, Varki A, Stamenkovic I, Bevilacqua MP: Cytokineinduced beta-galactoside alpha-2,6-sialyltransferase in human endothelial cells mediates alpha 2,6-sialylation of adhesion molecules and CD22 ligands. J Biol Chem 1994, 269:10637-10643.

27. Malik S, Balkwill F: Epithelial ovarian cancer: a cytokine propelled disease? Br J Cancer 1991, 64:617-620.

28. Marth C, Zeimet AG, Herold M, Brumm C, Windbichler G, MullerHolzner $E$, Offner F, Feichtinger $H$, Zwierzina $H$, Daxenbichler $G$ : Different effects of interferons, interleukin- I beta and tumor necrosis factor-alpha in normal (OSE) and malignant human ovarian epithelial cells. Int J Cancer 1996, 67:826-830. 
29. Maguire TM, Coughlan CM, Seckl JR, Breen KC: The effect of corticosteroids on serum sialyltransferase enzyme activities in the rat. Biochim Biophys Acta 1998, 1379:23-28.

30. Wang XC, Smith TJ, Lau JT: Transcriptional regulation of the liver beta-galactoside alpha 2,6-sialyltransferase by glucocorticoids. J Biol Chem 1990, 265:17849-17853.

31. Vandamme V, Pierce A, Verbert A, Delannoy P: Transcriptional induction of beta-galactoside alpha-2,6-sialyltransferase in rat fibroblast by dexamethasone. Eur J Biochem 1993, 2II: I35- 140 .

32. Sood AK, Bhatty R, Kamat AA, Landen CN, Han L, Thaker PH, Li Y, Gershenson DM, Lutgendorf S, Cole SW: Stress hormone-mediated invasion of ovarian cancer cells. Clin Cancer Res 2006, 1 2:369-375.

33. Peyrat JP, Recchi MA, Hebbar M, Pawlowski V, Hornez L, Dong-Lebouhris X, Hondermarck H, Harduin-Lepers A, Delannoy P: Regulation of sialyltransferase expression by estradiol and 4-OHtamoxifen in the human breast cancer cell MCF-7. Mol Cell Biol Res Commun 2000, 3:48-52.

34. Lau KM, Mok SC, Ho SM: Expression of human estrogen receptor-alpha and -beta, progesterone receptor, and androgen receptor mRNA in normal and malignant ovarian epithelial cells. Proc Natl Acad Sci USA 1999, 96:5722-5727.

35. Lessan K, Aguiar DJ, Oegema T, Siebenson L, Skubitz AP: CD44 and betal integrin mediate ovarian carcinoma cell adhesion to peritoneal mesothelial cells. Am J Pathol I999, I 54:I525-I537.

36. Casey RC, Burleson KM, Skubitz KM, Pambuccian SE, Oegema TR Jr, Ruff LE, Skubitz AP: Beta I-integrins regulate the formation and adhesion of ovarian carcinoma multicellular spheroids. Am J Pathol 200I, I 59:207I-2080.

37. Strobel T, Cannistra SA: Beta I-integrins partly mediate binding of ovarian cancer cells to peritoneal mesothelium in vitro. Gynecol Oncol 1999, 73:362-367.

38. Casey RC, Skubitz AP: CD44 and beta I integrins mediate ovarian carcinoma cell migration toward extracellular matrix proteins. Clin Exp Metastasis 2000, 18:67-75.

39. Burleson KM, Hansen LK, Skubitz AP: Ovarian carcinoma spheroids disaggregate on type I collagen and invade live human mesothelial cell monolayers. Clin Exp Metastasis 2004, 21:685-697.

40. Wang $X$, Zhang LH, Ye XS: Recent development in the design of sialyltransferase inhibitors. Med Res Rev 2003, 23:32-47.

4I. Wolfenden R, Frick L: Transition state affinity and the design of enzyme inhibitors. In Enzyme Mechanisms Edited by: Page M, Williams A. London: The Royal Society of Chemistry; 1987:97-I 22.

42. Kemmner W, Hohaus K, Schlag PM: Inhibition of Gal betal, 4GIcNAc alpha2,6 sialyltransferase expression by antisenseoligodeoxynucleotides. FEBS Lett 1997, 409:347-350.
Publish with Bio Med Central and every scientist can read your work free of charge

"BioMed Central will be the most significant development for disseminating the results of biomedical research in our lifetime. "

Sir Paul Nurse, Cancer Research UK

Your research papers will be:

- available free of charge to the entire biomedical community

- peer reviewed and published immediately upon acceptance

- cited in PubMed and archived on PubMed Central

- yours - you keep the copyright

Submit your manuscript here:

http://www.biomedcentral.com/info/publishing_adv.asp
BioMedcentral 